\title{
Reaction monitoring reveals poisoning mechanism of Pd2(dba) 3 and guides catalyst selection
}

DOI:

10.1039/C7CC08018B

Document Version

Accepted author manuscript

Link to publication record in Manchester Research Explorer

Citation for published version (APA):

Colletto, C., Bures Amat, J., \& Larrosa, I. (2017). Reaction monitoring reveals poisoning mechanism of Pd2(dba)3 and guides catalyst selection. Chemical Communications. https://doi.org/10.1039/C7CC08018B

\section{Published in:}

Chemical Communications

\section{Citing this paper}

Please note that where the full-text provided on Manchester Research Explorer is the Author Accepted Manuscript or Proof version this may differ from the final Published version. If citing, it is advised that you check and use the publisher's definitive version.

\section{General rights}

Copyright and moral rights for the publications made accessible in the Research Explorer are retained by the authors and/or other copyright owners and it is a condition of accessing publications that users recognise and abide by the legal requirements associated with these rights.

\section{Takedown policy}

If you believe that this document breaches copyright please refer to the University of Manchester's Takedown Procedures [http://man.ac.uk/04Y6Bo] or contact uml.scholarlycommunications@manchester.ac.uk providing relevant details, so we can investigate your claim.

\section{OPEN ACCESS}




\section{Journal Name}

\section{COMMUNICATION}

\section{Reaction monitoring reveals poisoning mechanism of $\mathbf{P d}_{2}(\mathrm{dba})_{3}$ and guides catalyst selection}

Received 00th January 20xx, Accepted 00th January 20xx

DOI: $10.1039 / x 0 x \times 00000 x$

\author{
Chiara Colletto, Jordi Burés* and Igor Larrosa*
}

www.rsc.org/

We have discovered that the dba ligand in the commonly used $\mathrm{Pd}_{2}(\mathrm{dba})_{3}{ } \mathrm{CHCl}_{3}$ cross-coupling pre-catalyst is susceptible to bisarylation when used in the presence of aryl iodides. The in situ formed $\mathrm{dbaAr}_{2}$ ligands result in Pd-species with altered catalytic activity. In the case of study, the room temperature $\mathrm{C} 3$ arylation of benzo[b]thiophenes with aryl iodides, we have observed a marked catalyst deactivation when dba is arylated with electrondeficient aryl iodides, accounting for the poor yields obtained in the $\mathrm{C} 3$ arylation reactions with these aryl iodides. Based on these studies, we report a new catalytic system, employing a dba-free Pd catalyst, which allows for the first time the direct C3-arylation of benzo[ $b]$ thiophenes with electron-deficient aryl iodides at room temperature.

Pd-catalyzed cross-couplings are one of the most powerful tools for the formation of carbon-carbon bonds. These methodologies usually require the employment of $\mathrm{Pd}(0)$ catalysts and are often used in combination with ligands such as phosphines or $\mathrm{N}$-heterocyclic carbenes (NHCs). ${ }^{1}$ Among the stable and phosphine-free $P d(0)$ sources, $P d_{x}(d b a)_{y}(x=1,2 ; y$ $=2,3$ ) complexes are certainly the most commonly used. ${ }^{2}$ Although $\mathrm{Pd}_{\mathrm{x}}(\mathrm{dba})_{\mathrm{y}}$ are often considered simple $\mathrm{Pd}(0)$ sources, pioneering studies by Amatore and Jutand on the rate of the oxidative addition of $\mathrm{Pd}_{\mathrm{x}}(\mathrm{dba})_{\mathrm{y}}$ complexes with aryl iodides in the presence of phosphines (L), revealed that the coordination ability of dba cannot be overlooked. ${ }^{3}$ Indeed, whereas $\mathrm{Pd}(\mathrm{dba}) \mathrm{L}_{2}$ did not undergo oxidative addition, dba-free $\mathrm{Pd}(0) \mathrm{L}_{2}$ complexes were instead shown to react with iodoarenes. Therefore, $\mathrm{Pd}(\mathrm{dba}) \mathrm{L}_{2}$ acts as reservoir, which slowly releases the active $\operatorname{Pd}(0) L_{2}$ species. In this context, Fairlamb and coworkers reported that $\mathrm{Pd}_{\mathrm{x}}\left(\mathrm{dba}-4,4^{\prime}-\mathrm{Z}\right)_{\mathrm{y}}$ complexes, featuring more electron-rich ancillary dba-4,4'-Z ligands (where $Z=$ electron-donating substituent), present an enhanced reactivity in cross-coupling reactions. This was attributed to a lowering of the $\pi$-accepting character of these dba- 4,4 '-Z ligands, which

\footnotetext{
School of Chemistry, The University of Manchester, Oxford Road, Manchester, M13 9PL.Email: igor.larrosa@manchester.ac.uk; jordi.bures@manchester.ac.uk

† Electronic Supplementary Information (ESI) available: Experimental procedures, NMR. See DOI: 10.1039/x0xx00000x
}

resulted in a more facile formation of catalytically active dbafree $\mathrm{Pd}(0)$ species. $^{4}$

On the other hand, the ancillary dba ligand has rarely been reported to itself react under the coupling conditions (Scheme 1). The group of Fairlamb, when studying Buchwald-Hartwig aryl amination reactions with $\mathrm{Pd}_{\mathrm{x}}\left(\mathrm{dba}-4,4^{\prime}-\mathrm{Z}\right)_{\mathrm{y}}$ complexes, were able to isolate small amounts of mono- and bis-aminated dba$Z$ ligand from these reaction mixtures. ${ }^{4 b, 5}$ Contrarily to their previous reports, the electronic nature of $d b a-4,4$ '-Z of the $\operatorname{Pd}(0)$ source did not significantly influence the catalytic efficiency of the system as the ligand was consumed in situ forming a more electron-rich derivative, with concomitant release of $\mathrm{Pd}(0) \mathrm{L}_{2}$. Another example of functionalization of $d b a$ ligand was described by Liu and Hartwig when investigating the mechanism of $\alpha$-arylation of azlactones catalyzed by $\mathrm{Pd}(\mathrm{dba})_{2}{ }^{6}$ A stable $\mathrm{Pd}(\mathrm{II})$ complex containing a ligand formed by reaction of dba with the azlactone accounted for the inhibitory effect of dba in the system (Scheme 1b). Indeed, reactions promoted by $\mathrm{Pd}(\mathrm{OAc})_{2}$ instead of $\mathrm{Pd}(\mathrm{dba})_{2}$ were reported to take place at lower temperature with a smaller excess of azlactone.

Recently, our group developed a $\beta$-selective $\mathrm{C}-\mathrm{H}$ arylation of (benzo)thiophenes with aryl iodides employing

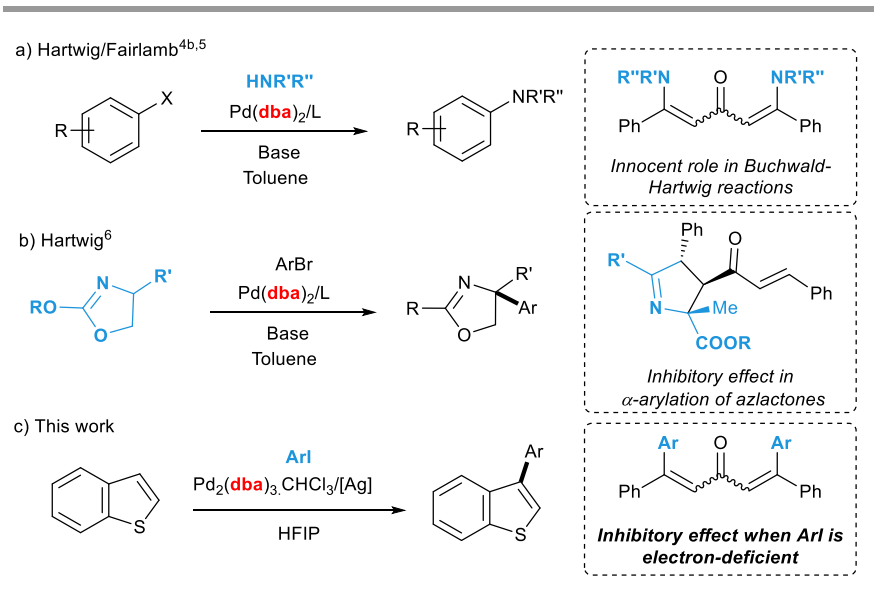

Scheme 1 In situ dba-modification in Pd couplings 
$\mathrm{Pd}_{2}(\mathrm{dba})_{3} \mathrm{CHCl}_{3}$ as the catalyst, a process which occurred under remarkably mild conditions. ${ }^{7,8}$ Notably, the first experimental evidence supporting a Heck-type pathway for the $\mathrm{C}-\mathrm{H}$ activation step in the arylation of heteroarenes was also disclosed. When investigating the scope of this methodology we realized that, while electron-rich iodoarenes reacted smoothly at room temperature, electron-deficient aryl iodides reacted sluggishly in yields of $10-42 \%$ under the standard conditions (Scheme 2).

Herein we report mechanistic investigations showing that an in situ arylation of the dba ligand in the Pd-precatalyst results in a catalytic system with altered reactivity (Scheme 1c). The reactivity of the resulting $\mathrm{Pd}^{-d b a A r}{ }_{2}$ complex markedly depends on the nature of the aryl iodide employed in the reaction and is responsible for the sluggish performance of electron-deficient aryl iodides. Based on these investigations, a new catalytic system has been identified capable of arylating benzo[b]thiophenes with electrondeficient aryl iodides at room temperature in good to excellent yields.

We began our mechanistic investigation by examining the kinetic profile of the reaction of benzo[b]thiophene $\mathbf{1 a}$ and 4iodotoluene $\mathbf{2 a}$, an aryl iodide displaying high reactivity (Fig. 1). ${ }^{9}$ A plot comparing formation of product 3 aa vs consumption of both starting materials indicated that, while consumption of benzo $[b]$ thiophene $\left([\right.$ reacted $\left.\mathbf{1 a}]=[\mathbf{1} \mathbf{a}]_{0}-[\mathbf{1} \mathbf{a}]\right)$ is consistent with formation of product 3aa, an abnormally high consumption of the aryl iodide $\mathbf{2 a}$ was observed (Fig. 1a). Interestingly, a second plot showing only the aryl iodide consumed in excess to that required to form product 3aa (ie ([2a $\left.\left.]_{0}-[\mathbf{2 a}]\right)-[3 \mathbf{a} a]\right)$ revealed that this additional consumption occurred exclusively during the first 1-2 $\mathrm{h}$ of reaction (Fig. 1b). Importantly, the aryl iodide consumed in excess totals 0.15 equiv, the exact amount that would be employed in bisarylating all of the dba present in the reaction. ${ }^{10}$ Intrigued by this possibility, we thoroughly examined the reaction crude after $2 \mathrm{~h}$ of reaction. Gratifyingly, we were able to isolate bisarylated dba $\mathbf{4 a}$ as a mixture of three stereoisomers, ${ }^{11}$
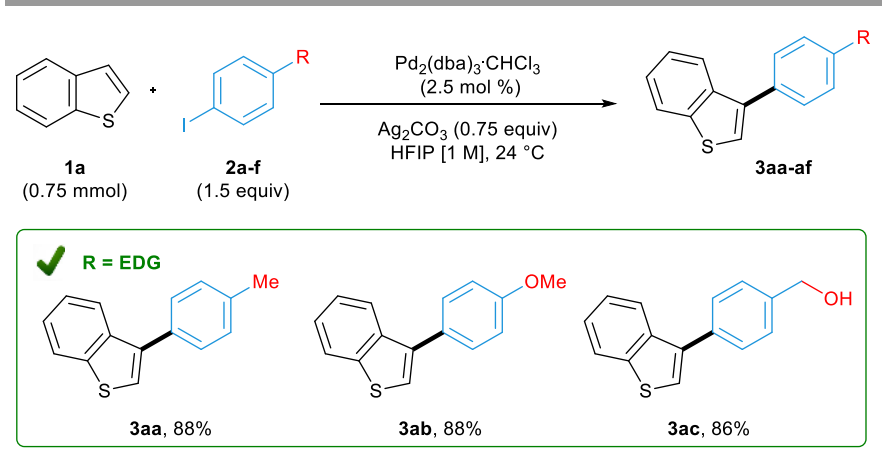

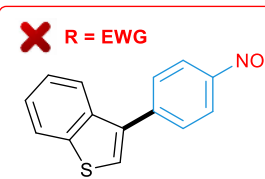

3ad, $30 \%$

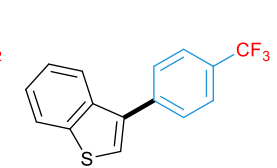

3ae, $10 \%$

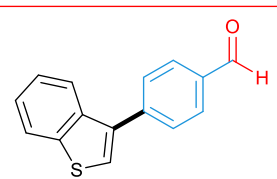

3af, $42 \%$

Scheme 2 Different reactivity of aryl iodides in room temperature Pd-catalyzed $\beta$-arylation of benzo[ $b]$ thiophene accounting for the observed consumption of aryl iodide $\mathbf{2 a}$. A closer look at the reaction profile shown in Fig. 1a suggests that bis-arylation of dba with 4-iodotoluene $2 \mathrm{a}$ does not have any significant effect in the efficiency of the catalytic system, with product 3aa obtained in $87 \%$ yield after $16 \mathrm{~h}$.

We then moved on to study the reaction between $\mathbf{1 a}$ and 1-iodo-4-nitrobenzene $\mathbf{2} \mathbf{d}$, an aryl iodide poorly reactive under our standard reaction conditions. Interestingly, a similar excess consumption of the aryl iodide was observed (Fig. 2a). A plot of excess aryl iodide consumed suggests that for this substrate the bis-arylation of dba also occurs quantitatively within the first $2 \mathrm{~h}$ of reaction (Fig. $2 \mathrm{~b}$ ). Also in this case, we were able to isolate bis-arylated $\mathrm{dba} \mathbf{4} \mathbf{d}$ as a mixture of three stereoisomers. ${ }^{12}$ In contrast to the reaction with the electronrich aryl iodide $\mathbf{2} \mathbf{a}$, analysis of the kinetic profile of the reaction with $\mathbf{2 d}$ clearly shows a significant decrease in reactivity of the catalytic system after the first $2 \mathrm{~h}$, with $24 \%$ of product $\mathbf{3 a d}$ being formed in that period, compared to only an additional $14 \%$ produced between 2 and $8 \mathrm{~h}$. In fact, comparison of initial rates of reaction between the systems in Fig. 1 and 2 would suggest that the reaction with the electron-deficient aryl iodide $\mathbf{2 d}$ is initially approximately twice as fast as that with aryl iodide $\mathbf{2 a}$, but significantly slows down as dba arylation progresses.

In order to gain further insights on the possible effect of

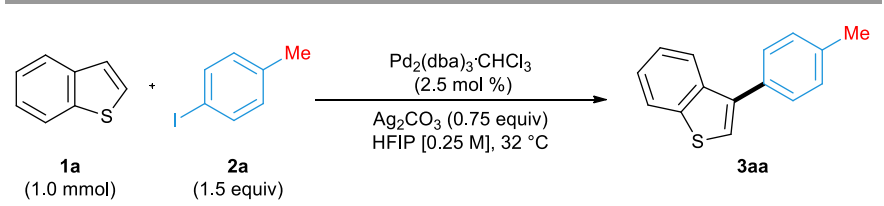

A
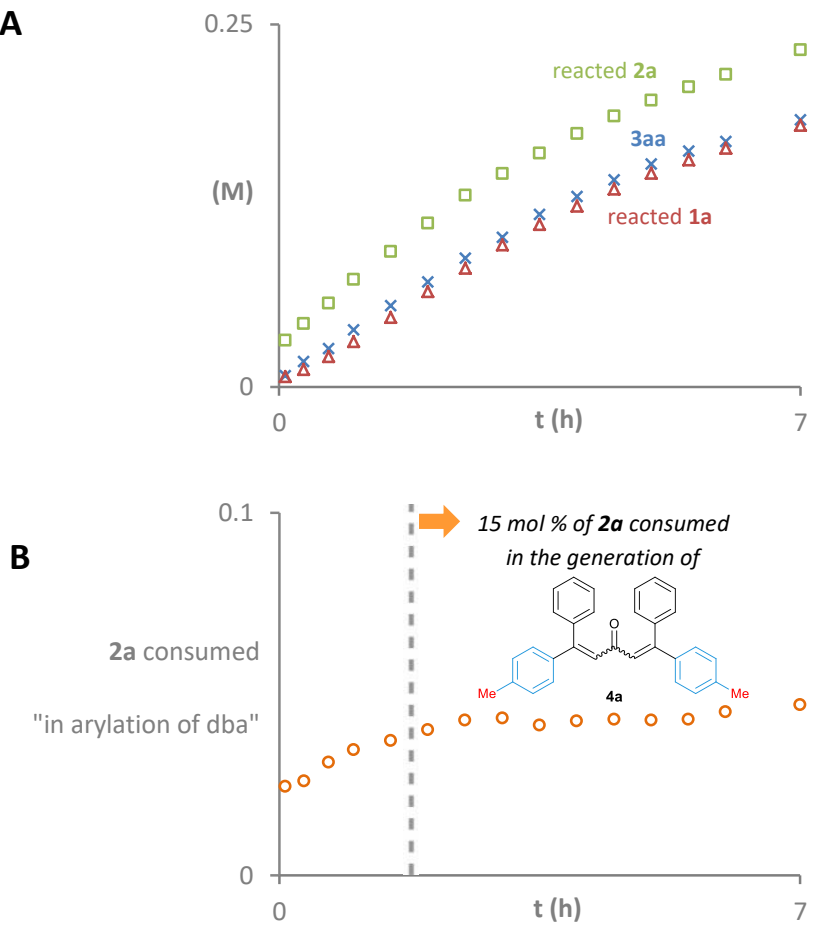

Fig. 1 A) Kinetic reaction profile for the $\beta$-arylation of benzo[ $b]$ thiophene 1a with

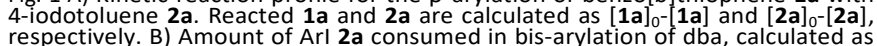
respectively. B) Amou 

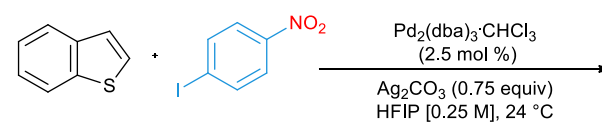

$\begin{array}{cc}1 \mathrm{a} & \mathbf{2 d} \\ (0.25 \mathrm{mmol}) & \text { (1.5 equiv) }\end{array}$

A

0.25

(M)

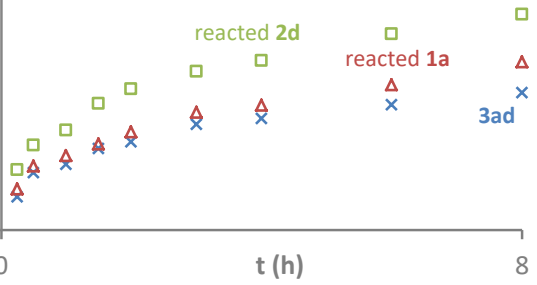

B

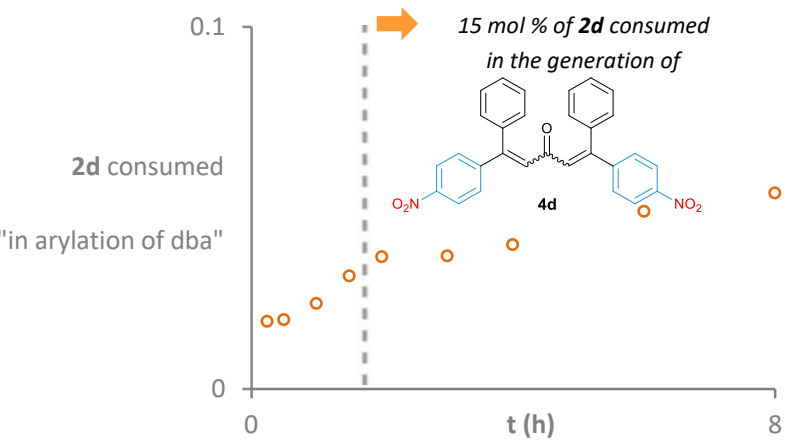

Fig. 2 A) Kinetic reaction profile for the $\beta$-arylation of benzo[b]thiophene 1 a with 1-iodo-4-nitrobenzene $\mathbf{2 d}$. Reacted $\mathbf{1 a}$ and $\mathbf{2 d}$ are calculated as $[\mathbf{1 a}]_{0}-[\mathbf{1 a}]$ and
[2d $]_{0}-[\mathbf{2 d}]$, respectively. B) Amount of Arl $\mathbf{2 d}$ consumed in bis-arylation of $\mathrm{dba}$, calculated as $\left([\mathbf{2 d}]_{0}-[\mathbf{2 d}]\right)-[\mathbf{3 a d}]$.

bis-arylation on the Pd-coordinating ability of dba, we evaluated in silico the Mulliken charge localized on the $\mathrm{C}=\mathrm{C}$ bonds of compounds 4a and $\mathbf{4 d} .^{13}$ Fairlamb and Lee have previously reported that, on $\mathrm{dba}-4,4^{\prime}-\mathrm{Z}(\mathrm{Z}=\mathrm{H}, \mathrm{EDG}, \mathrm{EWG}){ }^{4 \mathrm{~d}}$ this charge can be correlated with the reactivity of the Pd-catalyst, with higher charge leading to higher reactivity. This is explained by a lower capacity in coordinating $\mathrm{Pd}(0)$ as charge increases, through decreased $\pi$-backbonding. Our calculations show that there is a marked decrease in $\mathrm{C}=\mathrm{C}$ charge population upon bis-arylation with aryl iodide $\mathbf{2 d}$ $(-0.063)$ when compared to $2 a(-0.076)$, in line with the experimentally observed lower reactivity of the system when dba 4d is formed. These experimental and computational results suggest that upon bis-arylation $\mathrm{dbaAr}_{2} \mathbf{4 d}$ is more likely to remain associated to $\mathrm{Pd}$ than $\mathrm{dbaAr}_{2}$ 4a (or simple dba), thus negatively affecting the reactivity of the catalyst. ${ }^{14}$

We hypothesised that if bis-arylated dba 4 a could be formed first, the resulting catalytic system would display higher reactivity with electron-deficient aryl iodide $\mathbf{2 d}$, as formation of $\mathrm{dba} \mathbf{4} \mathbf{d}$ would be avoided. Thus, we treated $2.5 \mathrm{~mol}_{0} \mathrm{Pd}_{2}(\mathrm{dba})_{3} \mathrm{CHCl}_{3}$ with 0.15 equiv of 4 -iodotoluene $\mathbf{2 a}$ ( 2 equiv of $\mathbf{2 a}$ per $\mathrm{dba}$ ) in the presence of $\mathrm{Ag}_{2} \mathrm{CO}_{3}$ for $1.5 \mathrm{~h}$, leading to the in situ formation of $\mathrm{dbaAr}_{2} 4 \mathrm{a}$ and consumption of aryl iodide 2a (Scheme 3). To this 'pre-activated' catalyst we then added benzo[b]thiophene 1a and the normally poorly reactive electron-deficient aryl iodide $\mathbf{2 d}$. Remarkably, this protocol led to the formation of the desired product 3ad in an excellent yield of $74 \%$ at room temperature in $16 \mathrm{~h}$ compared to the previously observed $30 \%$, and confirming our hypothesis. ${ }^{15}$

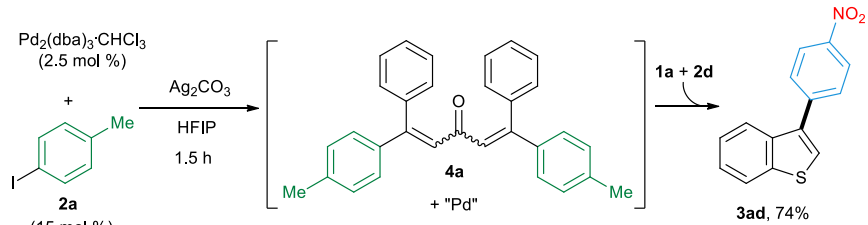

Active $P d$ catalyst generated

Scheme 3 Effect of pre-arylating dba with aryl iodide $2 a$, in the coupling between 1a and 2d. Reaction performed on a scale of $0.25 \mathrm{mmol}$ of 1a with 0.75 equiv of $\mathrm{Ag}_{2} \mathrm{CO}_{3}, 1.5$ equiv of $2 \mathrm{~d}$ and $\mathrm{HFIP}[0.25 \mathrm{M}]$ at $24{ }^{\circ} \mathrm{C}$. Yield given is calculated by
$\mathrm{H}-\mathrm{NMR}$ analysis using an internal standard.

Based on these results, we envisioned that a $\operatorname{Pd}(0)$ pre-catalyst containing a bis-arylated dba species such as 4 a would allow us to develop a general, high yielding room temperature coupling of benzo[b]thiophene 1a with electron-deficient iodoarenes. Unfortunately, attempts to synthesise such a complex were unsuccessful. ${ }^{16}$ As an alternative, we speculated that a dba-free $\mathrm{Pd}(\mathrm{II})$ source able to readily undergo reduction to $\mathrm{Pd}(0)$ under the reaction conditions may be a suitable alternative pre-catalyst for this transformation. Based on this, an assessment of Pd-species allowed us to identify $\mathrm{Pdl}_{2}$ as a highly reactive replacement for $\mathrm{Pd}_{2} \mathrm{dba}_{3}{ } \mathrm{CHCl}_{3}$ in the couplings between benzo[ $[b]$ thiophene and aryl iodides. $\mathrm{Pdl}_{2}$ may rapidly form $\mathrm{Pd}\left(\mathrm{OCH}\left(\mathrm{CF}_{3}\right)_{2}\right)_{2}$ upon exchange with $\mathrm{AgOCH}\left(\mathrm{CF}_{3}\right)_{2}$ which then may readily decompose to form $\mathrm{Pd}(0)$. With this new catalyst, we tested a variety of electron-deficient aryl iodides (Table 1).

Gratifyingly, the use of $\mathrm{Pdl}_{2}$ allowed the desired $\beta$-arylated products 3ad-3ao to be formed in good to excellent yields. $\mathrm{PdI}_{2}$ clearly exhibiting superior reactivity with respect to the dbacontaining Pd source (yields in brackets) in the cases where electron-withdrawing substituents were present at the para (3ad3af) and meta positions (3ag-3ak). Surprisingly, ortho-substituted

Table 1 Direct $\mathrm{C}-\mathrm{H}$ arylation of benzo[b]thiophene $\mathbf{1 a}$ with electron-poor iodoarenes $\mathbf{2 d - o a ^ { a }}$

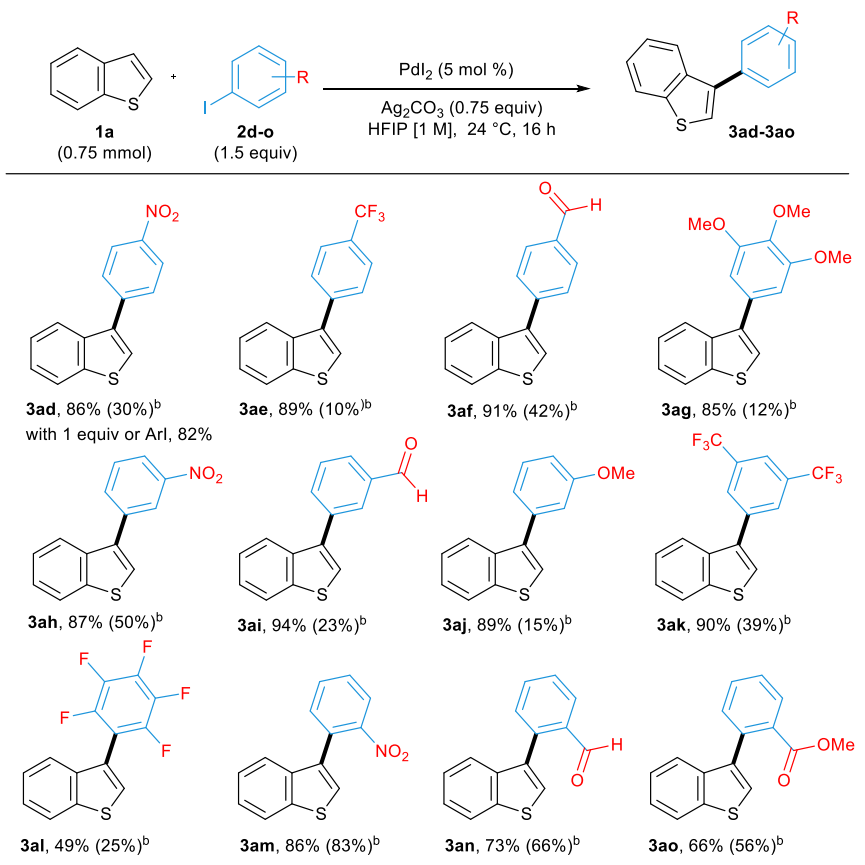

a Reactions carried out on a scale of $0.75 \mathrm{mmol}$ of 1a. Yields given are isolated. ${ }^{\mathrm{b}}$ Yields in brackets are using $\mathrm{Pd}_{2}(\mathrm{dba})_{3} \mathrm{CHCl}_{3}(2.5 \mathrm{~mol} \%)$ instead of $\mathrm{Pdl}_{2}$ and calculated by ${ }_{\mathrm{N}} \mathrm{H}$ NMR analysis using an internal standard. C3/C2 ratios were determined by
analysis of the crude reaction mixture and were greater than $98: 2$ in all cases. 
iodoarenes were similarly reactive under the two Pd sources, although the corresponding arylated products were obtained in slightly higher yields when $\mathrm{Pdl}_{2}$ was employed (3am-3ao). We speculate that the increased steric hindrance provided by the ortho-substituent may lead to a poorly coordinating bis-arylated $\mathrm{dba}$, thus resulting in a more highly reactive $\mathrm{Pd}$ species. Finally, in the coupling with 1-iodo-4-nitro-benzene $\mathbf{2 d}$, a reduced loading of 1.0 equiv of aryl iodide was tested without significantly affecting the formation of desired product 3ad (82\%).

In summary, we have described mechanistic studies showing the first example of an in situ bis-arylation of dba-ligand in a $\mathrm{Pd}_{2}(\mathrm{dba})_{3} \cdot \mathrm{CHCl}_{3}$ catalyzed process. This undesired arylation results in a modification of the catalytic species. The new species show significantly reduced reactivity when the added aryls groups are electron-deficient. Given the breadth of reported methods that use $\mathrm{Pd}_{\mathrm{x}} \mathrm{dba}_{\mathrm{y}}$ catalysts in combination with aryl iodide coupling partners, we speculate that this in situ catalyst modification could be a widespread phenomenon. Thus researchers developing new methods using these common Pd-catalyst precursors should take into account whether any alterations of $\mathrm{dba}$ occur and their possible impact on catalytic efficiency of the system. In the reaction under study, the room temperature arylation of benzo[b]thiophene, we found that high reactivity with electron-deficient aryl iodides can be achieved by switching the $\mathrm{Pd}$ catalyst from $\mathrm{Pd}_{2}(\mathrm{dba})_{3}{ } \mathrm{CHCl}_{3}$ to $\mathrm{Pdl}_{2}$, thus avoiding any issues with dba-arylation and in situ catalyst modification.

\section{Acknowledgements}

We gratefully acknowledge the European Research Council for a Starting Grant (to I.L.) and the EPSRC (EP/K039547/1). We thank Dr Ralph Adams (UoM) for the NMR experiments related to the identification of the bis-arylated dba compounds $\mathbf{4 a}$ and $\mathbf{4 d}$.

\section{Conflicts of interest}

There are no conflicts to declare.

\section{Notes and references}

1 (a) A. de Meijere, F. Diederich, Metal-Catalyzed CrossCoupling Reactions, Wiley-VCH, Weinheim, 2004; (b) S. P. Nolan, $\mathrm{N}$-Heterocyclic Carbenes in Synthesis, Wiley- $\mathrm{VCH}$, Weinheim, 2006, pp. 1-304; (c) F. Glorius, N-Heterocyclic Carbenes in Transition Metal Catalysis, Springer-Verlag, Berlin, 2006, pp. 1-218.

2 For selected applications of $\mathrm{Pd}_{x}(\mathrm{dba})_{y}(\mathrm{x}=1,2 ; \mathrm{y}=2,3)$ complexes see: (a) A. F. Littke, G. C. Fu, Angew. Chem., Int. Ed., 2002, 41, 4176-4211; (b) M. Cong, Y. Fan, J.-M. Raimundo, J. Tang, L. Peng, Org. Lett., 2014, 16, 4074-4077; (c) S. S. Zalesskiy, V. P. Ananikov, Organometallics, 2012, 31, 2302-2309.

3 (a) C. Amatore, A. Jutand, F. Khalil, M. A. M'Barki, L. Mottier, Organometallics, 1993, 12, 3168-3178; (b) C. Amatore, A. Jutand, G. Meyer, Inorg. Chim. Acta, 1998, 273, 76-84; (c) C. Amatore, A. Jutand, Coord. Chem. Rev., 1998, 178-180, 511528.

4 (a) I. J. S. Fairlamb, A. R. Kapdi, A. F. Lee, Org. Lett., 2004, 6, 4435-4438; (b) I. J. S. Fairlamb, A. R. Kapdi, A. F. Lee, G. P.
McGlacken, F. Weissburger, A. H. M. de Vries, L. Schmiedervan de Vondervoort, Chem. Eur. J., 2006, 12, 8750-8761; (c) Y. Macé, A. R. Kapdi, I. J. S. Fairlamb, A. Jutand, Organometallics, 2006, 25, 1795-1800; (d) I. J. S. Fairlamb, A. F. Lee, Organometallics, 2007, 26, 4087-4089; (e) I. J. S. Fairlamb, Org. Bio. Chem., 2008, 6, 3645-3656; (f) P. Sehnal, H. Taghzouti, I. J. S. Fairlamb, A. Jutand, A. F. Lee, A. C. Whitwood, Organometallics, 2009, 28, 824-829.

5 J. F. Hartwig, M. Kawatsura, S. I. Hauck, K. H. Shaughnessy, L. M. Alcazar-Roman, J. Org. Chem., 1999, 64, 5575-5580.

6 X. Liu, J. F. Hartwig, Org. Lett., 2003, 5, 1915-1918.

7 C. Colletto, S. Islam, F. Juliá-Hernández, I. Larrosa, J. Am. Chem. Soc., 2016, 138, 1677-1683.

8 For selected examples of $\beta$-arylation of (benzo)thiophenes in the absence of directing groups, see: (a) K. Ueda, S. Yanagisawa, J. Yamaguchi, K. Itami, Angew. Chem., Int. Ed., 2010, 49, 8946-8949; (b) S. Kirchberg, S. Tani, K. Ueda, J. Yamaguchi, A. Studer, K. Itami, Angew. Chem., Int. Ed., 2011, 50, 2387-2391; (c) K. Funaki, T. Sato, S. Oi, Org. Lett., 2012, 14, 6186-6189; (d) D.-T. D. Tang, K. D. Collins, F. Glorius, J. Am. Chem. Soc., 2013, 135, 7450-7453; (e) K. Yuan, H. Doucet, Chem. Sci., 2014, 5, 392-396; (f) D.-T. D. Tang, K. D. Collins, J. B. Ernst, F. Glorius, Angew. Chem., Int. Ed., 2014, 53, 1809-1813; (g) Z. Wang, Y. Li, B. Yan, M. Huang, Y. Wu, Synlett, 2015, 26, 531-536; (h) Y. Maki, T. Goto, N. Tsukada, ChemCatChem, 2016, 8, 699-702.

9 Product 3aa has been obtained in $74 \%$ yield after $7 \mathrm{~h}$.

10 The plot also shows that 0.10 equiv of aryl iodide $2 \mathbf{a}$ are consumed very fast, whereas a further 0.5 are consumed more slowly. This suggests that two out of the three dba in the $\mathrm{Pd}_{2} \mathrm{dba}_{3}$ precatalyst are bis-arylated faster than the remaining one. This can be explained by considering the initial formation of 0.05 equiv of $\mathrm{Pd}(0)$-dba and 0.025 equiv of free dba, followed by fast bis-arylation of the Pd-bound $\mathrm{dba}$, which would consume 0.10 equiv of $2 \mathrm{a}$. Slow ligand exchange with the remaining free-dba is then required before it is bis-arylated using further 0.05 equiv of $2 a$.

11 4a was obtained as a mixture of $(E, E):(Z, E):(Z, Z)$ isomers in ratio 6:1:traces as confirmed by NMR techniques $\left({ }^{1} H\right.$ NMR, COSY, selective 1D NOESY, ${ }^{13}$ C NMR and HSQC).

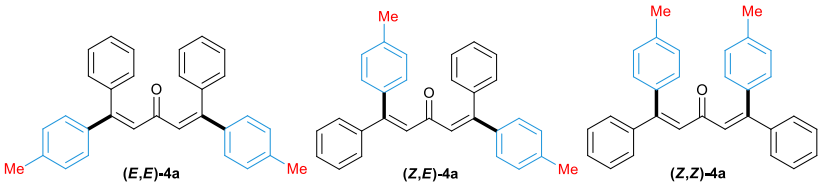

$12 \mathbf{4 d}$ was obtained as a mixture of $(E, E):(Z, E):(Z, Z)$ isomers in ratio $0.9: 1:<0.1$ as confirmed by NMR techniques $\left({ }^{1} H\right.$ NMR, COSY, selective 1D NOESY, selective $1 \mathrm{D}$ TOCSY, ${ }^{13} \mathrm{C}$ NMR and HSQC).

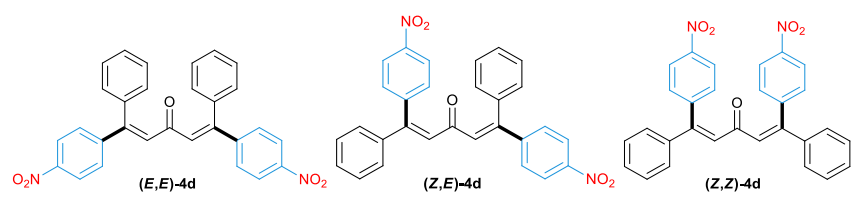

13 Geometries, frequency optimizations, Mulliken charge populations were calculated by DFT using Gaussian. B3LYP and $6-311 G(d, p)$ were respectively used as functional and basis set for the calculations. See SI for details.

14 A. A. Sabino, A. H. L. Machado, C. R. D. Correia, M. N. Eberlin, Angew. Chem., Int. Ed., 2004, 43, 2514-2518.

15 For several control experiments on the effects of dba prearylation, see SI.

16 The protocols tested are the ones reported by Fairlamb and co-workers for the synthesis of $\mathrm{Pd}_{x}(\mathrm{dba}-\mathrm{Z})_{\mathrm{y}}(\mathrm{x}=1,2 ; \mathrm{y}=2,3)$ complexes [ref. 4c]. In all cases only Pd-black was obtained. 